\title{
Photographic Evidence of Bobcats, Lynx rufus, in the Kananaskis Valley in Southwestern Alberta
}

\author{
NIKHIL LOBO ${ }^{1}$ and JOHN S. MiLlaR \\ Department of Biology, University of Western Ontario, London, Ontario N6A 5B7 Canada \\ ${ }^{1}$ Corresponding author e-mail: Nikhil Lobo <nlobo3@uwo.ca>
}

Lobo, Nikhil, and John S. Millar. 2010. Photographic evidence of Bobcats, Lynx rufus, in the Kananaskis Valley in southwestern Alberta. Canadian Field-Naturalist 124(3): 260-262.

During a study on the foraging behaviour of small mammals in the Kananaskis Valley, Alberta, in August 2009, we obtained video evidence of the presence of a Bobcat (Lynx rufus). This is the first confirmed Bobcat sighting in this region of southwestern Alberta.

Key Words: Bobcat, Lynx rufus, distribution, Kananaskis Valley, Alberta.

The distribution of the Bobcat (Lynx rufus) in Alberta is uncertain. They are believed to be present in very low numbers compared to the other native Alberta cats, the Cougar (Puma concolor) and the Canadian Lynx (Lynx canadensis) (Soper 1964; Pattie and Fisher 1999). Although Bobcats are active year-round, evidence of their presence is rare because they mostly move about at night, and are extremely shy and secretive (Soper 1964; Hansen 2007). Confirmed records (both sightings and specimens) of their presence in Alberta are scarce (Rand 1948; Soper 1964; Smith 1993). This has led to vague estimates of their distribution.

Using documented occurrences, Smith (1993) estimated the Bobcat's distribution in Alberta as being in the grasslands south of Cypress Hills, west along the Milk River drainage basin, and north along the foothills of the Rocky Mountains (Figure 1). However, Woelfl and Woelfl (1994) found evidence of their presence along the shoreline of the South Saskatchewan River on Canadian Forces Base Suffield $\left(50^{\circ} 32^{\prime} \mathrm{N}\right.$, $\left.110^{\circ} 32^{\prime} \mathrm{E}\right)$, well north of this described distribution (Figure 1). They are also believed to be found in the eastern portion of the Red Deer River valley (Soper 1964; Banfield 1974).

During a study on the foraging behaviour of small mammals in the Kananaskis Valley in southwestern Alberta, we obtained video evidence of the presence of a Bobcat. In the summer of 2009, infrared cameras (Sony DCR-SR65, Sony of Canada Ltd., Toronto, Ontario) were set up to monitor rodent activity at feeding trays in a coniferous forest stand just off Highway 68 $\left(51^{\circ} 03.08^{\prime} \mathrm{N}, 114^{\circ} 57.55^{\prime} \mathrm{W}\right.$; see Figure 1 for location). On August 10, 2009 at 1:50am MDT, one of our cameras recorded the limbs and feet of a large cat walking past it (Figure 2). The combination of the length of the hind foot (approximately $14.6 \mathrm{~cm}$ ) (Rand 1948; Larivière and Walton 1997), dark spots on the limbs (Rand 1948; Soper 1964; Hansen 2007), and direct register gait (Hansen 2007) indicated that the animal was a Bobcat, as opposed to the other Alberta cats. Lynx can have light grey spots on their limbs, but the length of their hind feet range from $21.0 \mathrm{~cm}$ to $25.0 \mathrm{~cm}$, and they have a straddle/overstep gait while walking (Tumlinson 1987; Elbroch 2003). Cougar cubs, but not adults, possess spotted fur, but they also do not have a direct register gait while walking, and the size of the hind foot we observed was too large for a cub (Elbroch 2003; Shaw et al. 2007). Lynx and Cougars have shown a direct register gait only when walking in snow (Elbroch 2003), but it had not snowed for almost two and a half months prior to our sighting.

Our study area was composed of thin stands of mature white spruce forest, mossy ground-cover, and nearby talus slopes. These features are ideal for Bobcats, who prefer to avoid dense forests (Rand 1948; Soper 1964; Smith 1993; Pattie and Fisher 1999). However, Bobcat sightings are rare in this area. One of the co-authors of this paper (J.S.M.) has seen Bobcats only a few times in more than 30 years working in the area, and only much further south, past Highwood Pass $\left(50^{\circ} 36.10^{\prime} \mathrm{N}, 114^{\circ} 58.56^{\prime} \mathrm{W}\right)$. Alexander and Gailus (2005) reported finding Bobcat snow-tracks along the Trans-Canada Highway west of Banff, approximately 

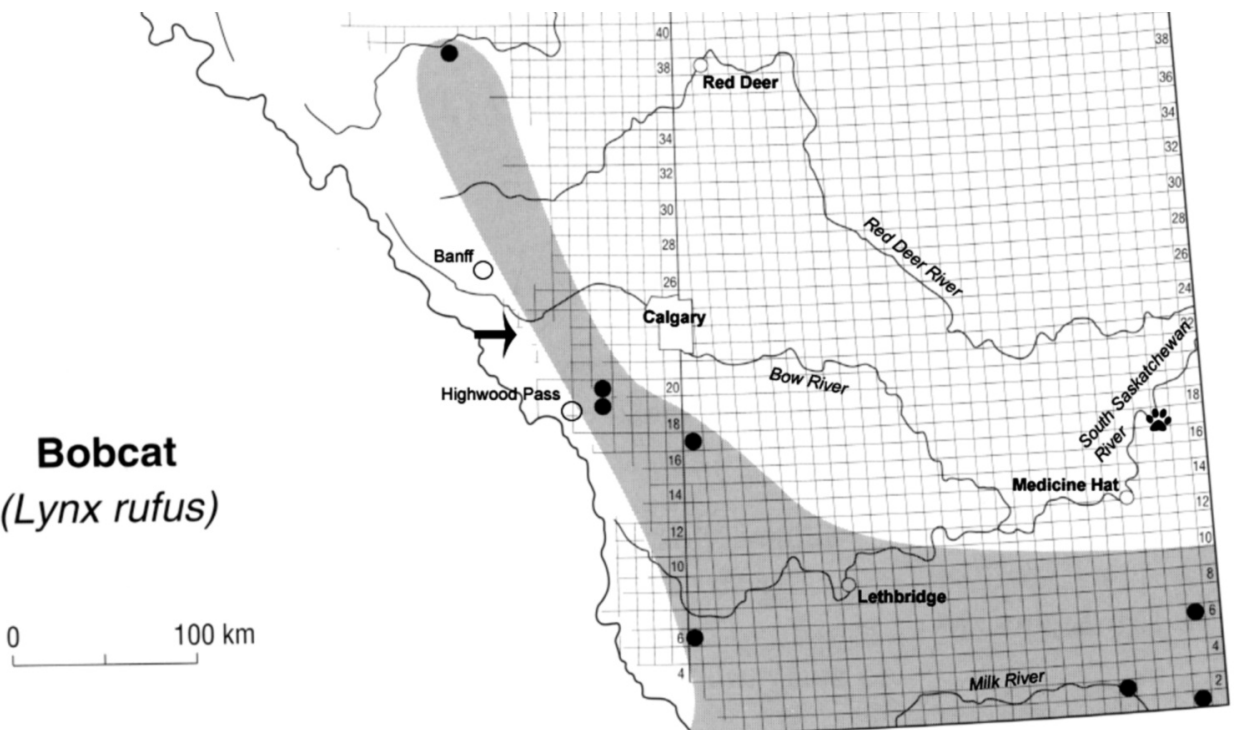

FIGURE 1. Reported distribution (shaded area) of the Bobcat in southern Alberta, from Smith (1993). Numbers displayed on the Alberta-Saskatchewan border (fourth meridian, $110^{\circ} \mathrm{W}$ longitude) and vertically through Calgary (fifth meridian, $114^{\circ} \mathrm{W}$ longitude) represent east-west township lines. Closed circles represent confirmed reports of Bobcats (Smith 1993). The paw print indicates the location of Bobcat tracks found at Canadian Forces Base Suffield (Woelfl and Woelfl 1994). The arrow indicates the location of our sighting.

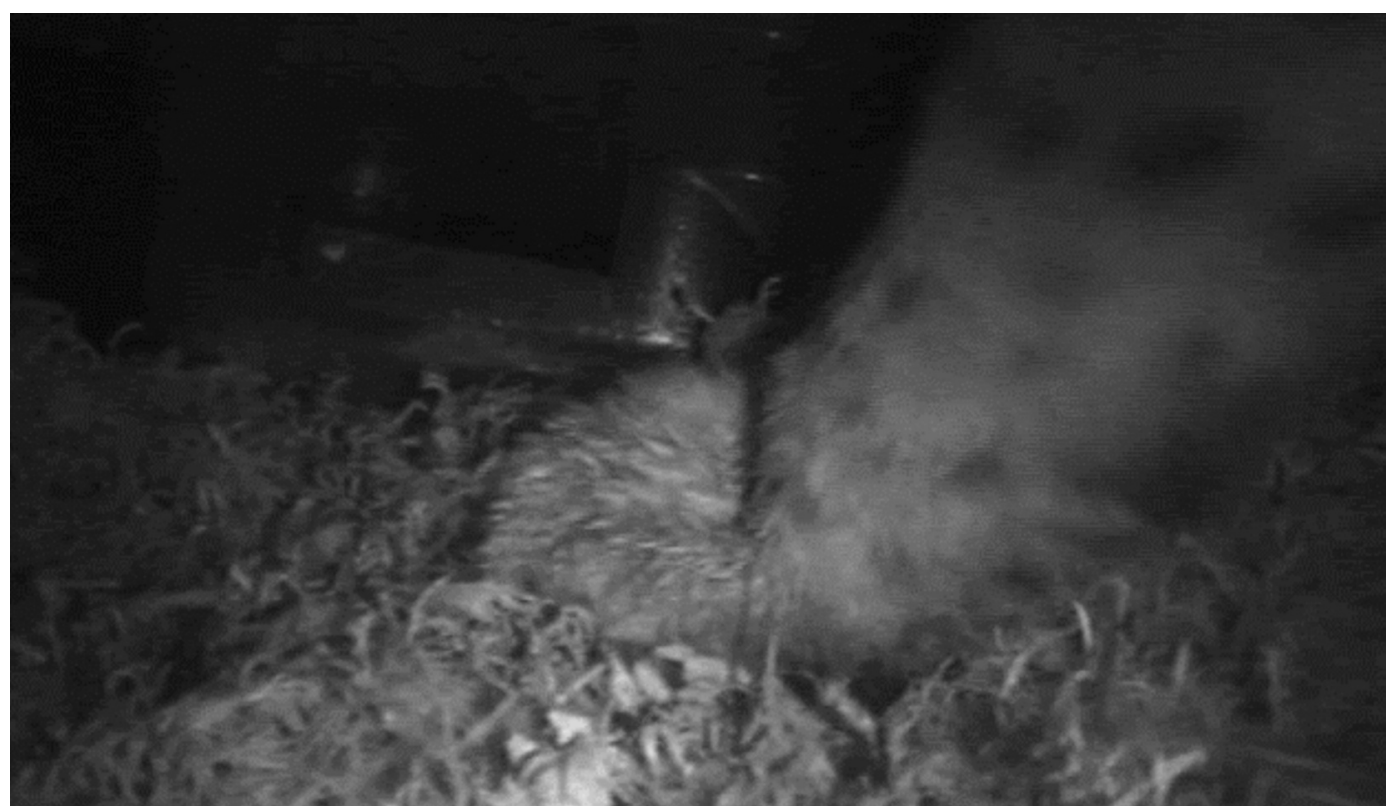

FIGURE 2. Snapshot from the video footage of the front limb of a Bobcat, recorded on 10 August 2009 at 1:50am 
$60 \mathrm{~km}$ northwest of our sighting. Research staff at the nearby University of Calgary Biogeoscience Institute and wildlife biologists at the local Fish and Wildlife Division of Alberta Sustainable Resource Development (Canmore, Alberta) have received only a few unconfirmed sightings in the past 10 years (J. BuchananMappin, personal communication; J. Jorgenson, personal communication). It became mandatory as of 2007 to report all Bobcat pelts harvested in Alberta to Sustainable Resource Development (Edmonton, Alberta), but zero have been registered from the Kananaskis Valley (R. Corrigan, personal communication). Prior to 2007, provincial fur harvest records from Registered Fur Management Areas within the Kananaskis Valley show that one Bobcat pelt was reported in 1992; however, these records are considered unreliable, and a large number of the Bobcat pelts reported in the province prior to 2007 were most likely Lynx (R. Corrigan, personal communication). While reported distributions estimate that Bobcats might be found along the foothills of the Rocky Mountains (Smith 1993), to our knowledge, this is the first confirmed, photographic evidence of a Bobcat present in this region of the Kananaskis Valley. The distribution of this elusive species likely extends further into the Rocky Mountains than previously thought.

\section{Acknowledgments}

We thank the staff at the Biogeoscience Institute of the Canadian Rockies and Foothills (University of Calgary), especially J. Buchanan-Mappin for her comments. We also thank J. Jorgenson (Fish \& Wildlife Division, Canmore, Alberta) and R. Corrigan (Wildlife Management Branch, Edmonton, Alberta) at Alberta Sustainable Resource Development for their comments, and the Royal Alberta Museum for granting us permission to reproduce their published Bobcat distribution map. We are grateful to C. T. Harding, C. Ibbotson, and R. C. White for their assistance in the field. Comments by three anonymous reviewers greatly improved an earlier version of the manuscript. The original study was funded by grants to J.S.M. from the Natural Sciences and Engineering Research Council of Canada.

\section{Literature Cited}

Alexander, S., and J. Gailus. 2005. A GIS-Based Approach to Restoring Connectivity Across Banff's Trans-Canada Highway (Technical Report \#4). Yukon to Yellowstone Conservation Initiative, Canmore, Alberta. 45 pages.

Banfield, A. W. F. 1974. The mammals of Canada. University of Toronto Press, Toronto, Ontario. 438 pages.

Elbroch, M. 2003. Mammal Tracks \& Sign: A Guide to North American Species. Stackpole Books, Mechanicsburg, Pennsylvania. 779 pages.

Hansen, K. 2007. Bobcat: Master of Survival. Oxford University Press, New York, New York. 248 pages.

Lariviere, S., and L. R. Watson. 1997. Lynx rufus. Mammalian Species 563: 1-8.

Pattie, D., and C. Fisher. 1999. Mammals of Alberta. Lone Pine Publishing, Edmonton, Alberta. 240 pages.

Rand, A. L. 1948. Mammals of the eastern Rockies and western plains of Canada (Bulletin No. 108). National Museum of Canada, Ottawa, Ontario. 237 pages.

Shaw, H. G., P. Beier, M. Culver, M. Grigione. 2007. Puma Field Guide: A guide covering the Biological Considerations, General Life History, Identification, Assessment, and Management of Puma concolor. The Cougar Network, Concord, Massachusetts. 129 pages.

Smith, H. C. 1993. Alberta Mammals: An Atlas and Guide. The Provincial Museum of Alberta, Edmonton, Alberta. 239 pages.

Soper, J. D. 1964. The mammals of Alberta. The Hamley Press Ltd. Edmonton, Alberta. 402 pages.

Tumlinson, R. 1987. Felis lynx. Mammalian Species 269: 1-8.

Woelfl, M., and S. Woelfl. 1994. Evidence of Bobcats, Lynx rufus, in southeastern Alberta. Canadian Field-Naturalist 108(4): 495-496.

Received 21 April 2010

Accepted 22 June 2010 